\title{
Changes in teacher-student relationships
}

\section{Citation}

Gehlbach, Hunter, Maureen E. Brinkworth, and Anna D. Harris. 2012. Changes in teacherstudent relationships. British Journal of Educational Psychology

\section{Published Version}

doi:10.1111/j.2044-8279.2011.02058.x

\section{Permanent link}

http://nrs.harvard.edu/urn-3:HUL.InstRepos:9276706

\section{Terms of Use}

This article was downloaded from Harvard University's DASH repository, and is made available under the terms and conditions applicable to Other Posted Material, as set forth at http:// nrs.harvard.edu/urn-3:HUL.InstRepos:dash.current.terms-of-use\#LAA

\section{Share Your Story}

The Harvard community has made this article openly available.

Please share how this access benefits you. Submit a story.

\section{Accessibility}


Running head: CHANGES IN TEACHER-STUDENT RELATIONSHIPS

\title{
Changes in teacher-student relationships
}

\author{
Hunter Gehlbach, Maureen E. Brinkworth, Anna D. Harris \\ Harvard University
}

\section{Word count (exc. figures/tables): 4967}

*Requests for reprints should be addressed to Hunter Gehlbach, 328 Longfellow, 13 Appian Way, Cambridge, MA, 02138 USA (e-mail: hunter_gehlbach@harvard.edu).

Author Note

This research was supported by generous funding through a grant from the Spencer Foundation, an Early Career Research Award by Division 15 of the American Psychological Association, and the National Academy of Education/Spencer Foundation post-doctoral fellowship program. The authors are particularly grateful for the generous assistance of the six participating schools. Rebecca Zazove provided invaluable assistance in helping to collect these data.

Please address all correspondence to Hunter Gehlbach:

Hunter_Gehlbach@gse.harvard.edu. 
Running head: CHANGES IN TEACHER-STUDENT RELATIONSHIPS

\section{Structured Abstract:}

Background: Although teacher-student relationships lie at the heart of students' schooling experience, fundamental questions regarding these relationships remain unanswered.

Aims: This study investigates three related questions about these relationships: To what extent do they change from the beginning to the end of a school year? Are any emergent changes associated with shifts in students' academic or motivational outcomes? Are certain "upstream" factors associated with improvements or declines in teacher-student relationships?

Sample: We investigate these questions with a sample of middle school students $(N=119)$ and their teachers $(N=30)$.

Methods: Through a novel approach which accounts for both perspectives within teacherstudent relationships, we assess these relationships at the beginning and end of the school year. Using multi-level models, we examine how changes in these relationships are associated with changes in students' grades, homework completion rates, self-efficacy, and effort. In addition, we examine associations with two potential precursors to teacher-student relationships: students' accuracy in taking their teachers' perspective and their perceptions of similarity to their teachers. Results: We find that substantial changes occur in these relationships from the beginning to the end of the year; these changes are associated with shifts in important student outcomes; and changes in students' social perspective taking accuracy and perceived similarity to their teachers correspond with changes in teacher-student relationships.

Conclusions: Given the malleability of teacher-student relationships and their importance for key achievement and motivational outcomes, we advocate for researchers to conduct field experiments to inform how to improve these critical relationships.

Keywords: achievement; adolescence; effort; middle school; motivation; self-efficacy; similarity; social perspective taking; social processes / development; teacher-student relationships 
Running head: CHANGES IN TEACHER-STUDENT RELATIONSHIPS

\section{Changes in teacher-student relationships}

For 30 years, I've been covering school reform and we've basically reorganized the bureaucratic boxes - charters, private schools, vouchers - but we've had disappointing results year after year. And the fact is, people learn from people they love. And if you're not talking about the individual relationship between a teacher and a student, you're not talking about that reality. But that reality is expunged from our policy-making process.

- David Brooks during his March 2011 TED talk

As David Brooks intimates, teacher-student relationships are among the most fundamental factors in successful schooling. What is especially striking about teacher-student relationships is not just that they matter, but that they appear consequential for such an extraordinary number and variety of academic and motivational outcomes for students (Juvonen, 2006).

In this article, we extend the research on teacher-student relationships by examining how they change from the beginning to the end of a single school year. At present, substantial evidence shows that teacher-student relationships are associated with important student outcomes at one point in time as well as from one year to the next. However, there is a paucity of information about whether these relationships change from the beginning to the end of a school year, whether any changes that occur correspond with changes in educational outcomes, or whether any student characteristics (particularly malleable characteristics) are associated with positive changes in teacher-student relationships. Extending our knowledge to include what happens during the school year is important for two reasons. First, because teachers can only reasonably hope to affect the relationships with students during the year that those students are in their classroom, looking within a single school year may provide important insights for practitioners. Second, from a scientific standpoint, if changes in these relationships correspond with changes in important student outcomes within a school year, it provides additional 
Running head: CHANGES IN TEACHER-STUDENT RELATIONSHIPS

information as to whether some of these associations might be causal - an important lingering question in this area.

\section{Teacher-Student Relationships}

We begin by briefly reviewing the extant evidence connecting teacher-student

relationships to a broad array of student outcomes. We find substantial evidence that the positive aspects of teacher-student relationships are associated with achievement and motivational outcomes. For example, students who perceive that their teachers are more supportive have better achievement outcomes on standardized math tests (Midgley, Feldlaufer, \& Eccles, 1989) and English grades (Goodenow, 1993). Teachers' high expectations for their students also correspond with better end-of-year grades (Wentzel, 2002). Students who think their teachers are caring pay more attention during class (Wentzel, 1997). More supportive and caring teachers have more motivated students as measured by effort and self-efficacy (Goodenow, 1993; Murdock \& Miller, 2003).

The inverse is also true. Negative aspects of teacher-student relationships correspond to worse student outcomes across achievement and motivational domains. Hamre and Pianta (2001) found that teacher-student conflict was consistently related to lower grades in math and English. Those students who form weaker social bonds with their teachers are more likely to be disengaged or feel alienated (Murdock, 1999). Furthermore, persistent negativity in the relationships between teachers and students has been implicated in students' decisions to drop out of school (Fine, 1991).

The link between teacher-student relationships and important outcomes extends to longitudinal research - including some remarkably durable associations. Hamre and Pianta (2001) found associations between students' level of conflict in their teacher-student 
Running head: CHANGES IN TEACHER-STUDENT RELATIONSHIPS

relationships in kindergarten and their grades as seventh and eighth graders. Murdock, Anderman, and Hodge (2000) found that students' views of their teachers' expectations of them in seventh grade better predicted their future college plans than students' own perceptions of their academic abilities. Across the transition into junior high school, Midgley, et al. (1989) found that elementary school teachers' supportiveness was predictive of students' valuing of, and intrinsic interest in, mathematics.

Although we generally know more about these relationships at the elementary level, there is good reason to think that they are especially critical during secondary school. Stageenvironment fit theory (Eccles, Lord, \& Roeser, 1996) provides some insight into why. According to this theory, emerging adolescents have different needs at different developmental stages. Better student outcomes result as the fit improves between adolescents' needs and the environment's capacity to meet those needs. Particularly during early adolescence, students often look to non-parental adults for social bonds, yet as they transition into middle school, their teacher-student relationships tend to be less personal and less positive (Eccles et al., 1993). Thus, in terms of relationships with teachers, students' fit in elementary school is often better than during middle school. However, assuming development continues throughout the year (and students vary in their relationship needs within a classroom), then stage-environment fit theory might reasonably be extended to look at changes within a school year (and variability between students). In other words, students or their teachers might change over the course of the year such that the nature of the teacher-student relationship becomes a better (or worse) fit for the students' developmental needs. 
Running head: CHANGES IN TEACHER-STUDENT RELATIONSHIPS

\section{The Present Research}

To summarize, abundant evidence suggests that teacher-student relationships matter: how positive they are matters, how negative they are matters, they matter across numerous outcomes, they matter from one year to the next, and they matter for students of different ages. In fact, Pianta and Allen (2008) argue that at the secondary level "positive relationships with adults are perhaps the single most important ingredient promoting positive youth development" (p. 24). Yet, there is an oddity in this research. Despite knowing how important these relationships are, we know remarkably little about the changes that may take place in these relationships over the course of a single school year within a teacher's classroom. Do students and teachers size each other up early in the year and allow those first impressions to set the tone for the remainder of the year (see Gilbert, 1995 for a review of reasons why initial impressions tend to endure)... or do these relationships mirror the ups and downs typically found in marriages (e.g., Driver \& Gottman, 2004)?

If these relationships do change within a year, the next logical question is whether these changes are yoked with changes in important student outcomes such as their achievement or motivation. The increasing number of longitudinal findings that link teacher-student relationships with student outcomes may signal of the potential import of these relationships (i.e., if at least some of these associations are causal). However, this research predominantly looks across (rather than within) teachers. Thus, it remains unclear whether it is even plausible to think that teachers might cause improved student outcomes by enhancing their individual relationships with students.

Finally, if teacher-student relationships do change within a school year and these changes correspond with changes in important student outcomes, then the question becomes, what 
Running head: CHANGES IN TEACHER-STUDENT RELATIONSHIPS

"upstream" factors might be leveraged to improve teacher-student relationships. Might changes in certain malleable qualities of students' correspond with changes in the quality of their teacherstudent relationship? To the extent that changes in malleable characteristics are associated with improvements in teacher-student relationships, it could be a critical step towards ultimately developing interventions to improve these relationships. For example, one promising precursor to teacher-student relationships is social perspective taking - students' or teachers' capacity to discern the thoughts, feelings, and motivations of the other party, as well as understanding how the other party perceives the situation (Gehlbach, Brinkworth, \& Harris, manuscript under review-b). To the extent that students better understand their teachers' perspective, they may behave in ways that enhance the relationship (at least from their teacher's point of view). Furthermore, prior research documents clear avenues through which SPT may impact TSR: through improving communication (Nickerson, 1999), reducing stereotyping (Galinsky \& Moskowitz, 2000), heightening social awareness (Selman, 2003), and resolving conflicts (Gehlbach, 2004). Another pathway for improving teacher-student relationships includes perceived similarity. Cialdini (2009) summarizes a vast number of social psychological findings by noting that, similarity between oneself and others provides a powerful rule of thumb as to who will make good friends and associates.

From a teacher's point of view, these questions - about whether relationships can change, whether these changes matter, and what might facilitate changes in these relationships - may have important practical consequences. After all, teachers do not control students' teacherstudent relationships from the previous year, nor which students are assigned to their class. Clearly, the best chance that teachers have of influencing their relationship with their students is during the year they are in class together. Insights from the aforementioned questions may help 
Running head: CHANGES IN TEACHER-STUDENT RELATIONSHIPS

teachers better understand how much these relationships might change, how important those changes are, and what types of factors might be important influences on these relationships.

These questions also contribute scientific value to the growing body of work on teacherstudent relationships. Examining what happens to these relationships within a classroom during the school year provides new evidence regarding whether the teacher-student relationshipsstudent outcomes association may be causal. Prior longitudinal explorations of teacher-student relationships that examine students' relationships from one year to the next leave open the possibility that relatively static characteristics of teachers or students (e.g., years of teaching experience or personality traits) influence both the teacher-student relationship and student outcomes. In other words, maybe more experienced teachers foster both better teacher-student relationships and better student outcomes. However, if we find that changes in teacher-student relationships correspond with changes in student outcomes within a single school year, this possibility of a stable characteristic of teachers or students as the key causal factor seems much less likely (given that teachers' years of experience do not change within a single school year) at least for the population we investigate.

This study provides initial insights into these issues through an examination of three research questions:

1) To what extent do teacher-student relationships change over the course of a school year?

2) To the extent that these changes do occur, do they correspond to changes in student outcomes of import including academic achievement and motivation? 
Running head: CHANGES IN TEACHER-STUDENT RELATIONSHIPS

3) If these changes are related to valued student outcomes, are certain "upstream" characteristics of students, such as social perspective taking or similarity, associated with these changes?

To investigate these questions, we took a novel approach to measuring these relationships. Specifically, we noted that previous investigations of teacher-student relationships at the secondary level often focused on the students' perceptions of the relationship, tended to assess specific, discrete aspects of the relationship, and rarely distinguished the positive aspects of the relationship from the negative. This approach has worked well to assess certain research questions. However, leaving out teachers' perspectives regarding the teacher-student relationship omits crucial information about the relationship. Assessing discrete aspects of the relationship precludes the possibility that weaknesses in one area (e.g., encouragement) might be compensated for by strengths in another (e.g., caring). Finally, simply because there is an absence of positive regard between a teacher and a student, does not necessarily mean that there is active ill-will between the two (for more on positivity and negativity as separate dimensions, see Cacioppo \& Berntson, 1994). Thus, to complement this prior work, we developed parallel scales to assess teacher-student relationships from both teacher and student perspectives; we examined the relationships holistically (rather than examining discrete aspects such as support, respect, caring, etc.); and we distinguished the positive and negative dimensions of the relationship (Gehlbach, Brinkworth, \& Harris, manuscript under review-a).

\section{Methods}

These data were collected as part of a broader investigation of teacher-student relationships. Related research questions on teacher-student relationships are investigated in 
Running head: CHANGES IN TEACHER-STUDENT RELATIONSHIPS

Gehlbach, et al. (manuscript under review-b) and Gehlbach, Brinkworth, and Harris (manuscript under review-a).

\section{Participants}

Because of the importance of middle school as a time of developmental transition particularly with regard to social relationships (Eccles, et al., 1993) - we focused on early adolescence for this research. The participants in the sample were typical of many suburban middle schools in the United States of America. Students $(N=119 ; 50 \%$ female $)$ and teachers $(N=30 ; 67 \%$ female) were from a working-middle class community. The school was about average in its achievement levels as measured by state standardized test scores and $34 \%$ of students were on free or reduced lunch (Great Schools, 2011).

The total participation rate $^{1}$ (Hoynoski, Link, \& Frankel, 2009) - i.e., the fraction of students who participated out of the total number of students at the school was $23 \%$. In terms of racial composition, the students in our sample appeared generally representative of the larger student body. The student sample was predominantly White $(61 \%$ versus $71 \%$ for the larger student body) and Hispanic (10\% versus $17 \%$ for the larger student body). Our sample also included a large number of students who classified themselves in the mixed-race/other category $(23 \%)$ - this category was not used in the whole school data that we had access to (Great Schools, 2011). Students in $6^{\text {th }}$ grade represented $41 \%$ of the sample; $7^{\text {th }}$ graders comprised $33 \%$; and $8^{\text {th }}$ graders were $26 \%$. For the majority of students $(71 \%)$ English was the primary language spoken at home; for many of the remaining students the primary languages were Portuguese or a combination of Portuguese and English. The teachers in the sample were predominantly White $(93 \%)$.

\footnotetext{
${ }^{1}$ Total participation rate was preferred to response rate because response rate fails to account for portions of the sampling frame that were omitted (e.g., students who were absent on the day that the consent forms were sent home).
} 
Running head: CHANGES IN TEACHER-STUDENT RELATIONSHIPS

\section{Measures}

Measures in this study included four measures of teacher-student relationships, four student outcomes, and two measures that we thought might be associated with changes in teacher-student relationships. All measures were collected in the early fall and late spring of the school year, except for students' grades (which were collected only in spring).

Teacher-student relationship measures. Teachers and students completed parallel scales that we had developed previously (Gehlbach, Brinkworth, et al., manuscript under reviewa) in which teachers reported on one student at a time and students were assigned to report on a single teacher. The TSR positivity scale consisted of 9 items to assess the positivity of perceptions of the teacher-student relationship such as, "How friendly is <teacher's name/student's name $>$ toward you?" The reliabilities for students were $\alpha$ s $=.93$ pre, .95 post, and .82 change; while for teachers they were $\alpha$ s $=.86$ pre, .91 post, and .72 change. The TSR negativity scale (5 items) included questions such as "How angry does < teacher's name/student's name> make you feel during class?" Reliabilities for students were $\alpha$ s $=.76$ pre, .76 post, and .25 change; for teachers they were $\alpha \mathrm{s}=.73$ pre, .74 post, and .24 change.

Student outcomes. To assess students' achievement we examined students' selfreported grade in the class that they had with the teacher of interest. Because our initial data collection occurred before the first marking period, students' grades were collected only in the spring. To augment our sense of students' achievement through a behavioral indicator, we asked teachers to report the percentage of homework that students completed for their class. As indicators of students' motivation in the classes that they were reporting on, students reported their levels of self-efficacy as well as how much effort they expended for class. To assess selfefficacy, we adapted the scale used by Gehlbach et. al. (2008). This 5-item scale ( $\alpha$ s $=.87$ pre, 
Running head: CHANGES IN TEACHER-STUDENT RELATIONSHIPS

.87 post, and .52 change) assessed how confident students were with regard to different aspects of the course in question with items such as, "How confident are you that you can learn all the material presented in this class?" We developed a 5-item effort scale ( $\alpha$ s $=.82$ pre, .90 post, and .51 change) for the purposes of this study. Representative items include, "How much effort do you put forth for this class?"

\section{Potential "upstream" predictors of teacher-student relationships. We developed} measures for and assessed students' social perspective taking accuracy ${ }^{2}$ and perceived similarity to see whether changes in these variables corresponded with changes in teacher-student relationships. Students' social perspective taking accuracy was assessed using a similar approach to Luo and Snider (2009). Specifically, we asked students to predict how their teachers would respond to the teacher-student relationship items. For example, students were asked:

Please take your best guess as to how your teacher will answer the question, "How respectful is $<$ student's own name $>$ towards you?" To assess accuracy, scores were computed by correlating students' predictions with their teachers' actual self-report. Students' perceptions of how similar they were to their teachers, was measured through a 5 -item scale $(\alpha$ s $=.88$ pre, .90 post, and .67 change) using items such as, "How similar are your values to <teacher's name>'s values?”

Standard demographic data were also collected as well as other pertinent questions such as whether teachers had taught a particular student in class before (10\% of the students had been in that teachers class in a previous year).

Procedures. We recruited participants by first explaining the study to teachers to ensure that the majority were willing to participate. After obtaining teachers' consent, we sent consent

\footnotetext{
${ }^{2}$ We also included a measure of social perspective taking motivation i.e., how motivated students were to take their teachers' perspectives. Changes in this measure were not associated with changes in the other key constructs in this study. Though this measure is omitted here for the sake of parsimony, it is described in more detail elsewhere (Gehlbach, et al., manuscript under review-b).
} 
Running head: CHANGES IN TEACHER-STUDENT RELATIONSHIPS

forms home for students and their parents/guardians to sign, through students' homeroom teachers. Once we confirmed which students were participating, we obtained class schedules and randomly selected a participating focal teacher for each student. Based on the selected teacher, we then created individualized surveys for each student (i.e., a survey that referenced the student and focal teacher by name, as well as the specific class the student had with that teacher).

Fall data collection occurred as soon as teachers felt they knew each of their students well enough to report on their relationships (after about a month and a half of school). The spring data collection occurred as close to the end of the year as possible. A member of the research team administered the survey to students in paper and pencil format; no teachers were present during the administration. After receiving the student surveys, we sent each teacher a parallel form of the survey to complete at their own convenience and return to us within two weeks. These parallel forms included individualized sections for teachers to report on each of their students who were participating in the study.

\section{Results}

We present our results in three parts, corresponding to each research question. First, we document the extent to which change occurred in teacher-student relationships. Second, we illustrate how these changes in the perceptions of these relationships are associated with changes in achievement- and motivation-related outcomes of interest. Third, we examine the extent to which changes in social perspective taking accuracy and similarity are associated with changes in teacher-student relationships.

\section{(How much) do Teacher-Student Relationships Change?}

We examined the extent to which teacher-student relationships changed in several ways. First, we compared the overall mean changes from the beginning of the year to the end of the 
Running head: CHANGES IN TEACHER-STUDENT RELATIONSHIPS

year. As the paired sample t-tests in Table 1 illustrate, students' perceptions of TSR positivity declined significantly; the change in the other variables did not reach significance. The distributions of each change score provide another window into how much students' and teachers' perceptions of their relationships changed over the course of the year. Table 1 indicates that the standard deviations of the change-scores ranged from .48 for teachers' TSR negativity to .74 for students' TSR positivity. A raw frequency count shows that the vast majority of the teacher-student relationships changed. For students, 93\% (for TSR positivity) and 84\% (for TSR negativity) changed their perceptions. For teachers, $92 \%$ and $74 \%$ were the corresponding percentages. Though some of these changes are small and might be attributable to chance or measurement error, on the whole our data indicate that students' and teachers' perceptions of these relationships at the end of the year frequently differed from their initial perceptions.

$* * * * * * * * * * * * * * * * * * * * *$

Insert Table 1 about here

$* * * * * * * * * * * * * * * * * * * * * *$

It is also worth noting that changes in each party's perceptions of the relationship parallel, but do not replicate, changes in the other parties' perceptions. As Table 2 indicates, changes in students' perceptions of TSR positivity and TSR negativity correlate significantly, though modestly, with changes in teachers' perceptions of TSR positivity and TSR negativity.

$* * * * * * * * * * * * * * * * * * * * *$

Insert Table 2 about here

$* * * * * * * * * * * * * * * * * * * * *$

\section{Do these Changes Matter?}


Running head: CHANGES IN TEACHER-STUDENT RELATIONSHIPS

These changes are especially noteworthy to the extent that they correspond to changes in important student outcomes. To assess this second research question, we used multi-level models with maximum likelihood estimation (using Stata's xtmixed procedure) to fit models for our two achievement and two motivational outcomes. Each model nested students within teachers (ranging from 1 to 12 students per teacher) and contained the following predictors: students' perceptions of TSR positivity and TSR negativity and teachers' perceptions of TSR positivity and TSR negativity. Preliminary analyses indicated that differences in teacher-student relationships might emerge based on students' gender and mother's education level (though not factors such as race, subject matter of the class, etc.), thus we included student gender (male $=1$; female $=0$ ) and mother's education level as control variables in each model. By fitting the null model for each student outcome, we found that the intra-class correlations of the change-scores were: grades $=.10$, homework $=.37$, self-efficacy $=.14$, and effort $=.00$.

Through these analyses, we found that there were no significant associations between changes in teacher-student relationships and students' grades at the end of the year. In examining the percentage of homework that students completed, for students who submitted a greater percentage of their assignments at the end of the year than at the beginning, teachers tended to correspondingly increase how positively they felt about these students (Cohen's $d=$ .66). See Table 3.

In assessing aspects of students' motivation, we also found that changes in students' perceptions of TSR positivity (but not TSR negativity) were associated with changes in their selfefficacy in the class in question (Cohen's $d=.58$ ), as well as the amount of effort they reported expending in that class (Cohen's $d=.49)$.

$* * * * * * * * * * * * * * * * * * * * *$ 
Running head: CHANGES IN TEACHER-STUDENT RELATIONSHIPS

Insert Table 3 about here

$* * * * * * * * * * * * * * * * * * * * *$

\section{Are Certain "Upstream" Characteristics Associated with these Changes in Relationships?}

Our final research question investigated whether certain student characteristics that could be viewed as logical antecedents to teacher-student relationships were associated with changes in these relationships. Using the same multi-level modeling approach described above, we regressed each of the four measures of teacher-student relationships on different characteristics. Specifically, we fit four multi-level models (one for each measure of teacher-student relationships) that included student's social perspective taking accuracy and their perceptions of their similarity to their teachers (while again controlling for student gender and mother's educational level). The null models for the change in each teacher-student relationship outcome revealed intra-class correlations of: students' TSR positivity $=.02$, students' TSR negativity $=$ .00 , teachers' TSR positivity $=.11$, and teachers' TSR negativity $=.00$.

As shown in Table 4, changes in students' social perspective taking accuracy were associated with improved teacher-student relationships from both the student and teacher points of view. Effect sizes were all greater than 1 (Cohen's $d=1.16$ for students' TSR-positivity, $d=-$ 1.05 for students' TSR-negativity, $d=1.26$ for teachers' TSR-positivity, $d=-1.31$ for teachers' TSR-negativity). When students grew to perceive themselves as more similar to their teachers over the course of the year, the students also perceived greater TSR positivity and less TSR negativity in the relationships (Cohen's $d=.74$ for students' TSR positivity, $d=-.30$ for students' TSR negativity).

$* * * * * * * * * * * * * * * * * * * * *$

Insert Table 4 about here 
Running head: CHANGES IN TEACHER-STUDENT RELATIONSHIPS

$* * * * * * * * * * * * * * * * * * * * *$

\section{Discussion}

Our study sheds light on three preliminary questions regarding how teacher-student relationships change within a school year: does change occur, do these changes correspond with changes in important student outcomes, and what might lead to changes in these relationships?

To investigate these questions, we took a novel approach to assessing teacher-student relationships. Specifically, we employed a measure that accounted for both teachers' and students' perspective of the relationship, focused on the whole relationship, and assessed the positive and negative aspects of the relationship separately.

Our findings indicated that change clearly occurred in these relationships. The relationships tended to become less positive over the course of the year from students' perspectives. This result accords with much of the literature indicating that social and motivational outcomes for students tend to decline in middle school (Wigfield, Byrnes, \& Eccles, 2006). However, it is important to note that numerous teacher-student relationships in our sample did indeed improve. This finding reinforces the possibility that these relationships are malleable. For at least some teacher-student relationships, there may be steps that students or teachers can take to improve the relationships.

Next, we found that changes in these relationships were associated with changes in several student outcomes of import - homework submission, self-efficacy for the class in question, and effort. We did not find a comparable association between teacher-student relationships and students' grades. However, this may be a partial consequence of our only having one time point for this outcome. Although there are certainly many more student 
Running head: CHANGES IN TEACHER-STUDENT RELATIONSHIPS

outcomes that we could have examined, our findings serve as a proof of concept that changes in teacher-student relationships can be associated with important student outcomes.

Finally, we found significant associations with two "upstream" characteristics - students" social perspective taking of their teacher and their perceptions of similarity to their teacher. The malleability of these characteristics makes them attractive candidates as the loci for interventions. Social perspective taking has been improved through different types of interventions (Ekman \& Friesen, 2003; Gehlbach, Young, \& Roan, manuscript under review) and perceptions of similarity have a history of being successfully manipulated by social psychologists (Montoya, Horton, \& Kirchner, 2008). Thus, researchers might take advantage of these past successes in crafting classroom interventions.

We should note that these constructs are only theoretical pre-cursors to teacher-student relationships. On the one hand, people often begin "reading" others - either taking their perspective or assessing their level of similarity to oneself - the moment they are introduced. In this sense, both variables are logical precursors to teacher-student relationships because they will inevitably happen before a relationship is formed. On the other hand, these associations could be manifestations of reciprocal causality. People may also become more accurate at taking the perspective of, and see more similarities to, those with whom they develop stronger relationships.

\section{Limitations}

In addition to this question about causality, this research has other limitations that could be addressed through future studies. We prioritized wanting to shed light on several associations, i.e., those between teacher-student relationships, student outcomes, and factors that might influence those relationships. Thus, our research was designed to investigate whether 
Running head: CHANGES IN TEACHER-STUDENT RELATIONSHIPS

these types of associations exist; the intent was never to develop an exhaustive list of all the important outcomes and precursors to teacher-student relationships. Second, we were limited in being able to measure these relationships only at the beginning and end of the year - one consequence of which is that we had to use change scores rather than being able to model growth over three or more time points. Although a number of scholars have raised concerns about the use of change scores, these scores can be reliable (Rogosa \& Willett, 1983) and "can be an accurate and useful measure of individual change even in situations where the reliability is low," (Rogosa, Brandt, \& Zimowski, 1982, p. 730) ${ }^{3}$. Third, our findings are based upon a single middle school; thus, they are more likely to generalize to some schools than others. Finally, our investigation of student outcomes and "upstream" factors was limited to student characteristics teacher outcomes or qualities that are associated with teacher-student relationships fell outside the scope of our investigation. Future studies that can examine teacher-student relationships across multiple time points within a school year, at multiple schools, and with a broader array of measures (especially teacher measures), would be immensely useful.

\section{Conclusion}

With these limitations in mind, what lessons should be extracted from this research by scholars or by practitioners? From a scientific point of view, this research provides an important illustration that changes in teacher-student relationships are not just important from year to year, but that changes in these relationships within a school year also matter for important student outcomes. In tandem with exciting new research demonstrating that coaching teachers' on their teacher-student interactions caused learning gains as measured by standardized test scores (Allen, Pianta, Gregory, Mikami, \& Lun, 2011), it seems even more likely that improving

\footnotetext{
${ }^{3}$ Due to concern about the reliabilities of the teacher-student relationship negativity change scores, we re-analyzed the models in Table 3 without those scales included. Results were fundamentally unchanged.
} 
Running head: CHANGES IN TEACHER-STUDENT RELATIONSHIPS

teacher-student relationships might cause better student outcomes. Although more longitudinal research on these relationships within a school year would be helpful, it seems sufficiently likely that a causal connection exists between teacher-student relationships and at least some student outcomes for scholars to attempt field experiments to try to improve these relationships.

For practitioners, it is important to know that these relationships can (and do) change. Thus, teachers may wish to begin informally experimenting with practices that they think might help foster better relationships with their students. Though there are presumably an infinite number of ways to try and promote better teacher-student relationships, this research indicates that fostering improved perspective taking among students and helping students perceive similarities between themselves and their teachers may be promising starting places. Perhaps these practices might ultimately help researchers develop generalizable interventions to improve teacher-student relationships from both parties' perspectives.

If researchers and practitioners ultimately collaborate in improving teacher-student relationships and positive student outcomes ensue as a result, then perhaps teacher-student relationships can become more central to the policy debates about education. We might even speculate that more focus on these relationships could help to reverse the consistently disappointing results to which David Brooks refers in the opening of this article. 
Running head: CHANGES IN TEACHER-STUDENT RELATIONSHIPS

\section{References}

Allen, J. P., Pianta, R. C., Gregory, A., Mikami, A. Y., \& Lun, J. (2011). An interaction-based approach to enhancing secondary school instruction and student achievement. Science (New York, N.Y.), 333(6045), 1034-1037.

Cacioppo, J. T., \& Berntson, G. G. (1994). Relationship between attitudes and evaluative space: A critical review, with emphasis on the separability of positive and negative substrates. Psychological Bulletin, 115(3), 401-423.

Cialdini, R. B. (2009). Influence: Science and practice (5th ed.). Boston, MA: Pearson.

Driver, J. L., \& Gottman, J. M. (2004). Daily marital interactions and positive affect during marital conflict among newlywed couples. Family Process, 43(3), 301-314.

Eccles, J. S., Lord, S. E., \& Roeser, R. W. (1996). Round holes, square pegs, rocky roads, and sore feet: The impact of stage-environment fit on young adolescents' experiences in schools and families. In D. Cicchetti \& S. L. Toth (Eds.), Rochester symposium on developmental psychopathology, Vol. 7. Rochester: University of Rochester Press.

Eccles, J. S., Midgley, C., Wigfield, A., Buchanan, C. M., Reuman, D., Flanagan, C., et al. (1993). Development during adolescence: The impact of stage-environment fit on young adolescents' experiences in schools and in families. Special Issue: Adolescence. American Psychologist, 48(2), 90-101.

Ekman, P., \& Friesen, W. V. (2003). Unmasking the face: A guide to recognizing emotions from facial clues. Cambridge: Malor.

Fine, M. (1991). Framing dropouts: Notes on the politics of an urban public high school. Albany, N.Y.: State University of New York Press. 
Running head: CHANGES IN TEACHER-STUDENT RELATIONSHIPS

Galinsky, A. D., \& Moskowitz, G. B. (2000). Perspective-taking: Decreasing stereotype expression, stereotype accessibility, and in-group favoritism. Journal of Personality and Social Psychology, 78(4), 708-724.

Gehlbach, H. (2004). Social perspective taking: A facilitating aptitude for conflict resolution, historical empathy, and social studies achievement. Theory and Research in Social Education, 32(1), 39-55.

Gehlbach, H., Brinkworth, M. E., \& Harris, A. D. (manuscript under review-a). The benefits of assessing teacher-student relationships from both perspectives.

Gehlbach, H., Brinkworth, M. E., \& Harris, A. D. (manuscript under review-b). The promise of social perspective taking to facilitate teacher-student relationships.

Gehlbach, H., Brown, S. W., Ioannou, A., Boyer, M. A., Hudson, N., Niv-Solomon, A., et al. (2008). Increasing interest in social studies: Social perspective taking and self-efficacy in stimulating simulations. Contemporary Educational Psychology, 33(4), 894-914.

Gehlbach, H., Young, L. V., \& Roan, L. (manuscript under review). Teaching social perspective taking: How educators might learn from the army.

Gilbert, D. T. (1995). Attribution and interpersonal perception. In A. Tesser (Ed.), Advanced social psychology (pp. 98-147). New York: McGraw-Hill.

Goodenow, C. (1993). Classroom belonging among early adolescent students: Relationships to motivation and achievement. The Journal of Early Adolescence, 13(1), 21-43.

Great Schools. (2011). Your free online guide to K-12 schools. Retrieved 5-16-11, 2011, from $\underline{\text { www.greatschools.net }}$

Hamre, B. K., \& Pianta, R. C. (2001). Early teacher-child relationships and the trajectory of children's school outcomes through eighth grade. Child Development, 72(2), 625-638. 
Running head: CHANGES IN TEACHER-STUDENT RELATIONSHIPS

Hoynoski, B., Link, M., \& Frankel, M. (2009). Measuring total participation: An alternative metric to response rate. Paper presented at the 64th Annual Conference of the American Association for Public Opinion Research.

Juvonen, J. (2006). Sense of belonging, social bonds, and school functioning. In P. A. Alexander \& P. H. Winne (Eds.), Handbook of educational psychology. (pp. 655-674). Mahwah, NJ, US: Lawrence Erlbaum Associates Publishers.

Luo, S., \& Snider, A. G. (2009). Accuracy and biases in newlyweds' perceptions of each other: Not mutually exclusive but mutually beneficial. Psychological Science, 20(11), 13321339.

Midgley, C., Feldlaufer, H., \& Eccles, J. S. (1989). Student/teacher relations and attitudes toward mathematics before and after the transition to junior high school. Child Development, $60(4), 981$.

Montoya, R. M., Horton, R. S., \& Kirchner, J. (2008). Is actual similarity necessary for attraction? A meta-analysis of actual and perceived similarity. Journal of Social and Personal Relationships, 25(6), 889-922.

Murdock, T. B. (1999). The social context of risk: Status and motivational predictors of alienation in middle school. Journal of Educational Psychology, 91(1), 62-75.

Murdock, T. B., Anderman, L. H., \& Hodge, S. A. (2000). Middle-grade predictors of students' motivation and behavior in high school. Journal of Adolescent Research, 15(3), 327-351.

Murdock, T. B., \& Miller, A. (2003). Teachers as sources of middle school students' motivational identity: Variable-centered and person-centered analytic approaches. The Elementary School Journal, 103(4), 383-399. 
Running head: CHANGES IN TEACHER-STUDENT RELATIONSHIPS

Nickerson, R. S. (1999). How we know--and sometimes misjudge--what others know: Imputing one's own knowledge to others. Psychological Bulletin, 125(6), 737-759.

Pianta, R. C., \& Allen, J. P. (2008). Building capacity for positive youth development in secondary school classrooms: Changing teachers' interactions with students. In M. Shinn \& H. Yoshikawa (Eds.), Toward positive youth development: Transforming schools and community programs (pp. 21-39). Oxford: Oxford University Press.

Rogosa, D., Brandt, D., \& Zimowski, M. (1982). A growth curve approach to the measurement of change. Psychological Bulletin, 92(3), 726-748.

Rogosa, D., \& Willett, J. B. (1983). Demonstrating the reliability of the difference score in the measurement of change. Journal of Educational Measurement, 20(4), 335-343.

Selman, R. L. (2003). The promotion of social awareness: Powerful lessons from the partnership of developmental theory and classroom practice. New York: Russell Sage Foundation.

Wentzel, K. R. (1997). Student motivation in middle school: The role of perceived pedagogical caring. Journal of Educational Psychology, 89(3), 411-419.

Wentzel, K. R. (2002). Are effective teachers like good parents? Teaching styles and student adjustment in early adolescence. Child Development, 73(1), 287-301.

Wigfield, A., Byrnes, J. P., \& Eccles, J. S. (2006). Development during early and middle adolescence. In P. A. Alexander \& P. H. Winne (Eds.), Handbook of educational psychology (2nd ed., pp. 87-113). Mahwah, NJ: Lawrence Erlbaum. 
Table 1: Descriptive statistics for teacher-student relationship measures, outcomes, and potential precursors to teacher-student relationships

\begin{tabular}{|c|c|c|c|c|c|c|}
\hline \multirow[b]{3}{*}{1 Student TSR-positivity } & \multicolumn{2}{|c|}{ Time 1} & \multicolumn{2}{|c|}{ Time 2} & \multicolumn{2}{|c|}{ Change } \\
\hline & $N$ & Mean $(s d)$ & $N$ & Mean $(s d)$ & $N$ & Mean $(s d)$ \\
\hline & 113 & $3.59(.85)$ & 116 & $3.39(1.01)$ & 110 & $-.18(.74)^{*}$ \\
\hline 2 Student TSR-negativity & 113 & $1.69(.62)$ & 116 & $1.83(.73)$ & 110 & $.13(.54)$ \\
\hline 3 Teacher TSR-positivity & 112 & $3.75(.58)$ & 112 & $3.73(.70)$ & 106 & $-.02(.57)$ \\
\hline 4 Teacher TSR-negativity & 112 & $1.54(.52)$ & 112 & $1.65(.62)$ & 106 & $.10(.48)$ \\
\hline 5 Year-end grade & & & 113 & $87.45(11.68)$ & & \\
\hline 6 Homework & 82 & $82.09(21.06)$ & 74 & $80.31(22.90)$ & 53 & $-3.12(17.69)$ \\
\hline 7 Self-efficacy & 113 & $3.63(.80)$ & 116 & $3.65(.95)$ & 110 & $.04(.65)$ \\
\hline 8 Effort & 113 & $3.82(.78)$ & 116 & $3.70(.81)$ & 110 & $-.11(.61)$ \\
\hline 9 SPT Accuracy & 107 & $.66(.27)$ & 110 & $.61(.34)$ & 98 & $-.03(.33)$ \\
\hline 10 Similarity & 113 & $2.42(.82)$ & 116 & $2.31 \quad(.90)$ & 110 & $-.10(.69)$ \\
\hline
\end{tabular}

Notes:

1) $* \mathrm{p}<.05 ; * * \mathrm{p}<.01 ; * * * \mathrm{p}<.001$

2) Students' grades were collected only during the spring.

3) Significant differences were computed from paired sample t-tests with a Bonferroni correction based on the four significance tests for the TSR variables, the three outcomes, and the two precursors (respectively). 
Table 2: Correlations between change scores for teacher-student relationship measures, outcomes, and potential precursors to teacherstudent relationships

\begin{tabular}{|c|c|c|c|c|c|c|c|c|c|}
\hline & 1 & 2 & 3 & 4 & 5 & 6 & 7 & 8 & 9 \\
\hline 1 Student TSR-positivity & -- & & & & & & & & \\
\hline 2 Student TSR-negativity & $-.46 * * *$ & -- & & & & & & & \\
\hline 3 Teacher TSR-positivity & $.30 * *$ & $-.27 * *$ & -- & & & & & & \\
\hline 4 Teacher TSR-negativity & $-.38 * * *$ & $.35 * * *$ & $-.48 * * *$ & -- & & & & & \\
\hline 5 Year-end grade & $.21 *$ & -.07 & $.28 * *$ & $-.23 *$ & -- & & & & \\
\hline 6 Homework & $.41 * *$ & $-.30 *$ & $.53 * * *$ & $-.36 * *$ & $.49 * * *$ & -- & & & \\
\hline 7 Self-efficacy & $.38 * * *$ & -.06 & $.21 *$ & -.09 & .08 & .26 & -- & & \\
\hline 8 Effort & $.29 * *$ & -.05 & .16 & -.19 & .16 & $.31 *$ & $.50 * * *$ & -- & \\
\hline 9 SPT Accuracy & $.53 * * *$ & $-.42 * * *$ & $.43 * * *$ & $-.47 * * *$ & .16 & $.39 * *$ & $.38 * * *$ & $.23 *$ & -- \\
\hline 10 Similarity & $.60 * * *$ & $-.30 * *$ & .10 & $-.21 *$ & .01 & .20 & $.37 * * *$ & $.29 * *$ & $.29 * *$ \\
\hline
\end{tabular}

Notes:

1) $* \mathrm{p}<.05 ; * * \mathrm{p}<.01 ; * * * \mathrm{p}<.001$

2) All scores are change scores (i.e., year-end score minus initial score) except for year-end grade. 
Table 3: Multi-level model for changes in students' achievement and motivation outcomes: Unstandardized estimates and (SE)

\begin{tabular}{lrrrr}
\hline & \multicolumn{1}{c}{ Grades } & \multicolumn{1}{c}{ Homework } & Self-efficacy & Effort \\
\cline { 2 - 5 } Fixed effects & & & & \\
Student TSR-positivity & $1.63(1.66)$ & $2.00(2.81)$ & $.38(.10)^{* * *}$ & $.30(.09)^{* * *}$ \\
Student TSR-negativity & $1.32(2.36)$ & $.91(3.76)$ & $.18(.13)$ & $.17(.12)$ \\
Teacher TSR-positivity & $.56(2.13)$ & $11.72(5.02)^{*}$ & $.21(.13)$ & $.11(.11)$ \\
Teacher TSR-negativity & $2.02(2.58)$ & $-7.89(5.29)$ & $.11(.15)$ & $-.14(.13)$ \\
Student gender & $-3.18(2.18)$ & $8.44(4.15)^{*}$ & $.10(.13)$ & $.12(.11)$ \\
Mother's education & $1.89(.41)^{* * *}$ & $.28(.70)$ & $-.04(.02)$ & $-.05(.02)^{*}$ \\
Constant & $61.34(6.40)^{* * *}$ & $-10.56(10.62)$ & $.62(.36)$ & $.60(.32)$ \\
Random effects & & & & $.04(.03)$ \\
Variance between teachers & $.00(.00)$ & $109.62(67.50)$ & $.33(.05)$ & $.00(.00)$ \\
Variance between students & $105.76(15.35)$ & $119.48(32.20)$ & 177.09 & $.29(.04)$ \\
-2LL & 712.41 & 394.00 & & 155.63 \\
\hline
\end{tabular}

\section{Notes:}

1) $* \mathrm{p}<.05 ; * * \mathrm{p}<.01 ; * * * \mathrm{p}<.001$

2) All scores are change scores (i.e., year-end score minus initial score) except for year-end grade.

3) Student gender is coded $1=$ male, $0=$ female. 
Running head: CHANGES IN TEACHER-STUDENT RELATIONSHIPS

Table 4: Multi-level model for changes in perceptions of teacher-student relationships: Unstandardized estimates and (SE)

\begin{tabular}{|c|c|c|c|c|}
\hline & $\begin{array}{c}\text { Student TSR- } \\
\text { positivity }\end{array}$ & $\begin{array}{c}\text { Student TSR- } \\
\text { negativity }\end{array}$ & $\begin{array}{c}\text { Teacher TSR- } \\
\text { positivity }\end{array}$ & $\begin{array}{c}\text { Teacher TSR- } \\
\text { negativity }\end{array}$ \\
\hline \multicolumn{5}{|l|}{ Fixed effects } \\
\hline SPT Accuracy & $.86(.17) * * *$ & $-.57(.16) * * *$ & $.72(.15)^{* * *}$ & $-.63(.14) * * *$ \\
\hline Similarity & $.55(.08) * * *$ & $-.16(.07)^{*}$ & $.01(.07)$ & $-.06(.06)$ \\
\hline Student gender & $-.06(.11)$ & $-.08(.10)$ & $-.13(.10)$ & $.11(.09)$ \\
\hline Mother's education & $.04(.02)$ & $-.03(.02)$ & $.02(.02)$ & $-.02(.02)$ \\
\hline Constant & $-.62(.31)^{*}$ & $.54(.28)$ & $-.16(.28)$ & $.33(.25)$ \\
\hline \multicolumn{5}{|l|}{ Random effects } \\
\hline Variance between teachers & $.00(.00)$ & $.00(.00)$ & $.06(.03)$ & $.00(.00)$ \\
\hline Variance between students & $.28(.04)$ & $.22(.03)$ & $.18(.03)$ & $.17(.02)$ \\
\hline$-2 \mathrm{LL}$ & 151.00 & 130.00 & 127.55 & 101.84 \\
\hline
\end{tabular}

Notes:

1) $* \mathrm{p}<.05 ; * * \mathrm{p}<.01 ; * * * \mathrm{p}<.001$

2) All scores are change scores (i.e., year-end score minus initial score).

3) Student gender is coded $1=$ male, $0=$ female. 


\section{Appendix A}

Teacher-student relationship scale: Student and teacher items

\section{Positivity subscale}

1 How much do you enjoy learning from $<$ teacher's name $>$ ?

2 How friendly is <teacher's name $>$ toward you?

3 How often does $<$ teacher's name $>$ say something encouraging to you?

4 How respectful is $<$ teacher's name $>$ towards you?

5 How excited would you be to have <teacher's name $>$ again next year?

6 How motivating are the activities that <teacher's name> plans for class?

7 How caring is <teacher's name $>$ towards you?

8 How much do you like <teacher's name >'s personality?

9 Overall, how much do you learn from $<$ teacher's name $>$ ? Negativity subscale

1 How often do you ignore something <teacher's name $>$ says?

During class, how often do you talk when <teacher's

2 name> is talking (for instance, when you are supposed to be listening)?

3 How often does $<$ teacher's name $>$ say something that offends you?

4 How unfair is $<$ teacher's name $>$ to you in class?

5 How angry does $<$ teacher's name $>$ make you feel during class?
Teacher items

How much do you enjoy helping $<$ student's name $>$ learn?

How friendly is <student's name $>$ toward you?

How often do you say something encouraging to $<$ student's name >?

How respectful is <student's name $>$ towards you?

How excited would you be to have $<$ student's name $>$ again next year?

How motivating does < student's name $>$ find the activities that you plan for class?

How caring is $<$ student's name $>$ towards you?

How much do you like <student's name $>$ personality?

Overall, how much does $<$ student's name $>$ learn from you?

How often does $<$ student's name $>$ ignore something you say?

During class, how often does $<$ student's name $>$ talk when you are talking (for instance, when $<$ student's name $>$ is supposed to be listening)?

How often do you say something that offends $<$ student's name >?

How unfair are you to $<$ student's name $>$ in class?

How angry do you make $<$ student's name $>$ feel during class? 
Running head: CHANGES IN TEACHER-STUDENT RELATIONSHIPS

Notes:

Response anchors were arrayed along five points. For example: Not at all/Slightly/Somewhat/Quite a bit/A tremendous amount; Not at all friendly/Slightly friendly/Somewhat friendly/Quite friendly/Extremely friendly; Almost never/Once in a while/Sometimes/Frequently/Almost all the time; or Almost nothing/A little bit/Some/Quite a bit/A great deal. 